\title{
Significance of forms and foci of metacognitive regulation in collaborative science learning of less and more successful outcome groups in diverse contexts
}

\author{
Tuike liskala $^{1,2}$ (D) Simone Volet $^{3}$ (D) $\cdot$ Cheryl Jones $^{3}$ (D) $\cdot$ Milo Koretsky $^{4}$ (D) \\ Marja Vauras ${ }^{1,2}$ (D)
}

Received: 2 September 2019 / Accepted: 11 August 2021 / Published online: 13 September 2021 (c) The Author(s) 2021

\begin{abstract}
This study investigated how metacognitive regulation (MR), especially its forms and foci, was manifested in less and more successful outcome groups' collaborative science learning in diverse learning contexts. Whilst previous research has shown that different forms and foci of MR exist in collaborative learning, their role in groups' learning outcomes remains unexplored. Drawing conclusions from different studies has been difficult because these have used different conceptualisations and analytic methods. In the present study, the learning processes of less and more successful outcome groups from three diverse collaborative science learning contexts were scrutinised. The contexts differed in academic level, disciplinary subject, and national culture. The same theory-based conceptualisations, coding systems, coders, and analyses were used across contexts. In addition, the tasks studied were designed using the same guiding principles. Transcribed video and audio recordings of the groups' verbal interactions for two distinct interaction segments from these tasks formed the basis of the analyses. Manifestation of forms and foci of MR were quantitatively and qualitatively illustrated in each context. The main findings show that the manifestation of MR of less and more successful outcome groups demonstrated similarities and differences in the three different learning contexts. This study contributes to a contextualised understanding of MR in collaborative science learning, and highlights the importance of using similar, rigorous analytical tools across diverse contexts.
\end{abstract}

Keywords Metacognitive regulation - Socially shared metacognitive regulation · Collaborative learning $\cdot$ Learning outcome $\cdot$ Learning context $\cdot$ Science learning

Tuike Iiskala

tuike.iiskala@utu.fi

1 Department of Teacher Education, University of Turku, 20014 Turku, Finland

2 Centre for Research on Learning and Instruction (CERLI), Turku, Finland

3 School of Education, Murdoch University, Perth, WA 6150, Australia

4 Department of Education and Department of Chemical and Biological Engineering, Tufts University, Medford, MA, USA 


\section{Introduction}

Metacognitive regulation (MR) as the regulation of cognition has been associated with high-level learning outcomes in individual science learning (e.g., Akyol, Sungur, \& Tekkaya, 2010; Peters \& Kitsantas, 2010), but empirical research on this relationship in collaborative science learning is scarce. Empirical findings of the important role of MR in individual learning are not sufficient to claim its significance in collaborative learning (see Efklides, 2008; Rogat \& Linnenbrink-Garcia, 2011; Volet, Vauras, \& Salonen, $2009 \mathrm{~b})$ where learners are supposed to co-construct shared understanding of a problem (Hargreaves, 2007; Khosa \& Volet, 2014) towards a common goal (Dillenbourg, 1999; Roschelle \& Teasley, 1995). The definition of MR in collaborative learning implies that the quality of the group's ongoing cognitive learning process is monitored and controlled so that the group's collaborative work progresses toward a shared learning goal (see Schoor, Narciss, \& Körndle, 2015; Whitebread et al., 2009). On the basis that achievement of a group's goal is reflected in its learning outcome, examining the relationship of group learning outcome to engagement in MR is crucial to understand its significance in collaborative learning.

Previous research has explored MR's presence, nature, and characteristics in various collaborative science learning contexts (e.g. Iiskala et al., 2015; Ucan, 2017; Ucan \& Webb, 2015), but not necessarily its relationship to learning outcomes, that is, the quality of the group's collective product. Here the group is used as the unit of assessment for learning, rather than the individual, to reveal socially co-constructed understanding (see Hargreaves, 2007). This approach is supported by research findings of the effects of students' MR in collaborative learning that show a group's learning outcomes differ from individuals' learning outcomes (see Molenaar et al., 2012). Also, the few available research findings about the relationship between MR and group learning outcomes are inconclusive. For example, while Panadero and Järvelä (2015) discussed in their review positive associations between MR and group outcome quality, Schoor and Bannert (2012) reported that their less and more successful-outcome dyads did not differ in the amount of MR during collaborative learning, which led them to conclude that the dyads may not have benefited from MR. Thus, the role of the significance of MR in collaborative learning is not yet well established.

At least two conceivable explanations of the role of MR in collaborative learning can be advanced and are examined in the present research: first, the conceptualisation of MR in collaborative learning in terms of forms and foci may differ from what has been observed in individual learning since Flavell's (1976) seminal research. Applying merely the same conceptualization in collaborative learning as in individual learning may be inadequate since both social and individual processes manifest in collaborative learning (see Efklides, 2008). Second, the significance of the context in which MR in collaborative learning takes place may influence research results. The context contains specific characteristics such as the disciplinary subject (e.g. general science, veterinary medicine, engineering), academic level (e.g. high school, university), and national culture (Finland, Australia, United States). As Järvenoja, Järvelä and Malmberg (2015) highlighted, regulation in social learning situations is a unique combination of characteristics of that situation and needs to be studied in relation to its context. In the present study, forms and foci of MR are studied in relation to three diverse collaborative science learning contexts in order to acknowledge contextual features. 


\section{Conceptualisation of MR in collaborative learning in terms of forms and foci}

The literature on MR in collaborative learning in the last decade has identified its manifestation in terms of different forms and foci as crucial elements of the learning process (e.g. Grau \& Whitebread, 2012; Ucan \& Webb, 2015). The different forms of MR refer to whose cognitive process is regulated and how the group is involved in the MR process (see De Backer, Van Keer, \& Valcke, 2015; Iiskala, Vauras, \& Lehtinen, 2004; Malmberg, Järvelä, \& Järvenoja, 2017; Ucan, 2017; Whitebread et al., 2009; Volet et al., 2017), while the different foci refer to the level of cognitive activity (high, low) being regulated (cf., Grau \& Whitebread, 2012; Iiskala et al., 2011; Khosa \& Volet, 2014). To date however, research on the relationship of forms and foci of MR to the quality of the group's learning outcome has not been comprehensively examined. The present study addresses this gap by exploring this relationship in a systematic way, conceptually and methodologically, and in diverse contexts.

\section{Forms of MR in collaborative learning}

Previous research has conceptualised and empirically examined several forms of MR exploring the significance of regulation processes in collaborative learning (De Backer et al., 2015; Iiskala et al., 2004; Malmberg et al., 2017; Volet et al., 2017; Whitebread et al., 2009). These include: verbalised metacognitive self-regulation (VMSR; Volet et al., 2017, the verbalised manifestation of a well-established concept in the literature on individual learning, theoretically grounded in Brown, 1978 and Flavell's, 1976 seminal work); ignored MR (IMR; Molenaar, Sleegers, \& van Boxtel, 2014); metacognitive other regulation (MOR; Brown et al., 1983; Rogat \& Adams-Wiggins, 2014; Whitebread et al., 2009); and socially shared MR (SSMR; see e.g., Iiskala et al., 2015; Volet et al., 2013). Some studies (e.g., De Backer et al., 2015; Grau \& Whitebread, 2012; Ucan, 2017) have shown that, for example, VMSR and SSMR play out differently in groups' collaborative learning processes. For example, Grau and Whiteberad (2012) showed a positive relation between SSMR and discussion on relevant knowledge towards the learning goal. However, a similar positive relation was not found between VMSR and the appearance of goal-oriented relevant knowledge. These kinds of findings suggest that the significance of MR in collaborative learning needs to be examined in its varied forms rather than as a single overarching construct.

Verbalised metacognitive self-regulation (VMSR) in a collaborative learning setting refers to observable evidence of a group member's MR of their own learning despite the joint effort. Importantly, VMSR is influenced by the presence of others in the group (Volet, Summers, \& Thurman, 2009a), meaning that individual self-regulation and VMSR in collaborative learning differ from one another. In an individual context, selfregulation has been shown to promote learning since the learner regulates his or her own learning processes (e.g., Pintrich \& De Groot, 1990; Wang, Haertel, \& Walberg, 1990). In collaborative learning, VMSR has been observed to occur when an individual (temporarily), despite collective enterprise, attends to his or her own thinking processes rather than the group's shared learning process (see Grau \& Whitebread, 2012; Volet et al., 2009b; Whitebread et al., 2009). These findings suggest that VMSR may not have the same productive role in collaborative learning as metacognitive self-regulation has in an individual learning, although a group member's VMSR may trigger the group to 
engage in MR individually, and together (see Iiskala et al., 2004, 2011; Järvelä, Malmberg, \& Koivuniemi, 2016). In addition, most metacognitive self-regulation is assumed to be internal (i.e., not verbalised), and therefore not accessible to peers or researchers. Hence, we use the term of verbalised metacognitive self-regulation in the present study to make it explicit that we are only examining metacognitive self-regulation that is verbalised within a group setting. We acknowledge, however, that metacognitive self-regulation can take place without being verbalised but it is difficult to observe it and its selfregulatory influence or its benefits to peers. Using the concept of VMSR distinguishes it from the concept of self-regulation which is usually used for individual learning (see Schoor et al., 2015).

Ignored metacognitive regulation (IMR, a term coined by Molenaar et al., 2014) refers to a group member attempting to monitor and regulate the group's cognitive learning process, but the other group members ignore the attempt, for example, ignoring a student's suggestion to evaluate the accuracy of the group's conclusion (Molenaar et al., 2014). The occurrence of IMR has rarely been considered in collaborative learning, but Molenaar and colleagues provide important empirical evidence of IMR as dysfunctional MR activity during collaborative learning. Similarly, Rogat and Adams-Wiggins (2014) found IMR to be counterproductive in a group's collaborative balance because it can be used as a vehicle to exclude some members from the group effort, rather than to capitalise on the potential capacity of each. In research with highly motivated undergraduate students in veterinary medicine, Volet et al. (2017) found no evidence of IMR. These findings suggest that the emergence of IMR during a collaborative learning activity may be significantly affected by individual characteristics and learning setting.

Metacognitive other regulation (MOR) captures a social form of regulation, typically found in the literature on cognitive scaffolding (although not always labelled with reference to MR). MOR refers to the asymmetric metacognitive interaction between partners (Iiskala et al., 2004; Whitebread et al., 2009) in which one partner's learning is enhanced by the activity of a supportive other (see Brown et al., 1983). In unstructured, student-led, collaborative learning, MOR occurs when a student spontaneously and temporarily scaffolds another learner's thinking processes (see Iiskala et al., 2004; Rogat \& Adams-Wiggins, 2014; Whitebread et al., 2009). MOR is at its best when it facilitates other students' contributions toward high-level conceptual understanding, and supports the integration of varied ideas and group members' shared focus on the task (Mathabathe \& Potgieter, 2017; Rogat \& Adams-Wiggins, 2014). In contrast, as shown in Mathabathe and Potgieter's study, MOR is less than optimal when it inhibits quality learning outcomes and promotes regulation at a low cognitive level.

Finally, socially shared metacognitive regulation (SSMR) involves several group members' contributing to regulation of the joint cognitive activity. When regulated in a socially shared way, the learning process involves at least two students' regulatory involvement, as they interdependently affect the course of the cognitive learning process (see Iiskala et al., 2004, 2011, 2015; Volet et al., 2013). The socially shared nature of MR has been argued to be crucial because it represents a genuinely collective effort to regulate the progress of the group's cognitive activity (Iiskala et al., 2004, 2011; Järvelä et al., 2013). Empirical research has shown that SSMR helps small groups develop a shared understanding of the task, and sustain ongoing knowledge co-construction (Khosa \& Volet, 2014; Ucan \& Webb, 2015).

In sum, identifying the manifestations of these different forms of regulation during collaborative learning by examining their respective significance in the groups' learning outcomes appears essential. Only a few studies have systematically examined the significance 
of different forms of MR during collaborative learning (e.g., Grau \& Whitebread, 2012; Malmberg et al., 2017; Ucan \& Webb, 2015; Volet et al., 2017), and preliminary findings suggest that each can have a different impact on groups' collaborative learning processes.

\section{Foci of social forms of MR on high- and low-level cognitive activity in collaborative learning}

Previous research (e.g. Grau \& Whitebread, 2012; Khosa \& Volet, 2014; Ucan \& Webb, 2015) has indicated that the forms of MR cannot be separated from the focus of MR. In the same way that different forms of MR may support (e.g., SSMR; Ucan \& Webb, 2015; Volet et al., 2017) or inhibit (e.g. IMR; Molenaar et al., 2014; Rogat \& Adams-Wiggins, 2014) a group's collaborative learning, the focus of group members' cognitive activity being regulated should also be considered.

Prior research (e.g., Grau \& Whitebread, 2012; Iiskala et al., 2011; Järvelä et al., 2013; Khosa \& Volet, 2014; Malmberg et al., 2015; Volet et al., 2013) has pointed to crucial distinctions between the levels of cognitive activity that the individuals and the group engage in during collaborative learning. These different levels have been referred to as high- and low-level cognitive processing (e.g., Volet et al., 2009a) or high and low level activity (Khosa \& Volet, 2014). High-level cognitive activity has been empirically identified when the focus of the group was on elaboration and constructing meaning (Khosa \& Volet, 2014; Volet et al., 2009a); explaining relevant concepts, revealing a deep understanding (Järvelä et al., 2013), asking deeper-level questions requiring elaborated answers (Kempler \& Linnenbrink, 2006), or when directed at fundamental aspects of the task or knowledge (Grau $\&$ Whitebread, 2012), or at articulating a misconception or making explicit a lack of understanding (see Ucan \& Webb, 2015). In contrast, low-level cognitive activity has been identified when the focus was on simple acquisition of knowledge with no attempt at meaning making (Volet et al., 2009a) or listing concepts without explanation (Järvelä et al., 2013), or when it was on the practical, more contingent aspects of task production (Grau \& Whitebread, 2012; Khosa \& Volet, 2014), or performing the task using routine strategies without seeking conceptual understanding (Iiskala et al., 2011; Järvelä et al., 2013; Malmberg et al., 2015).

Engagement in both high- and low-level cognitive activity has been identified in the two social forms of MR, that is, in MOR and SSMR. For example, Mathabathe and Potgieter (2017) found that the focus of MOR could be at high-level when conceptual understanding is metacognitively regulated with explanation, but could also be at low level when students present information without any justification to improve understanding. Grau and Whitebread (2012) and Khosa and Volet (2014) noted that SSMR could focus on regulating both high- (i.e., fundamental knowledge, task concepts; conceptual understanding) and low(i.e., practical, organisational aspects of task production; identifying, collating knowledge and task information) level cognitive activity. Similarly, in mathematical learning, Iiskala et al. (2011) found that SSMR could also be applied to low-level, even incidental and irrelevant matters, moving away from understanding the core learning problem.

In turn, engagement in MR with a focus on high- or low-level cognitive activity has been found to differ between less and more successful outcome groups (Järvelä et al., 2013; Khosa \& Volet, 2014; Malmberg et al., 2015; Volet et al., 2013). In Khosa and Volet's (2014) study, the most and least successful groups did not differ regarding the proportion of their MR overall, but in terms of their regulatory focus on high- or low-level cognitive activity. The most successful outcome groups displayed a substantial amount of SSMR 
focusing on high-level cognitive activity, such as knowledge co-construction, revealing sustained attempts to develop shared conceptual understanding. In contrast, the SSMR displayed by the least successful outcome group tended to be applied to low-level cognitive activity, such as co-production of task deliverables: for example, discussing what was expected without any explicit conceptual association. The authors concluded that SSMR alone could not explain high-level scientific learning outcomes.

Similar findings were reported in Järvelä et al.'s (2013) study, in which the group that jointly regulated its high-level cognitive activity succeeded in the collaborative task, while the group that concentrated simply on task performance, neglecting regulation of deeper understanding or progress (i.e. low-level focus) showed only slight improvement, and did not perform as well. Similarly, Malmberg et al. (2015) found that low-performing groups regulated the external aspects of collaboration (i.e. low-level cognitive activity) or did not activate regulation at all. In contrast, high-performing groups adapted their regulation to the needs of the task and collaboration, and regulated, for example, their cognitive challenges (i.e., high level). In sum, there are several indicators that the focus of MR differs in less and more successful outcome groups, and that it is the case for both MOR and SSMR. Taken together, these findings call for the design of investigations on the significance of MR that also account for the co-occurrence of forms and foci during collaborative learning in diverse learning contexts, using the same conceptualisation of MR (in terms of forms and foci), and the same rigorous methods of data analysis.

\section{Significance of context in studies of MR in collaborative learning}

To date, the significance of context in research on MR in collaborative learning has not attracted much theorising nor systematic literature reviews. While contextual characteristics have been shown to contribute to how regulation manifests in collaborative learning processes (Järvenoja, Järvelä, \& Malmberg, 2015), the majority of studies of MR during collaborative learning have been conducted in a single learning setting with a single population. From a methodological perspective, comparisons between settings are hindered by the variety of analytical methods used (see Hadwin \& Oshige, 2011; Panadero \& Järvelä, 2015; Volet \& Summers, 2013; Volet et al., 2013). As Whitebread et al. (2009) and Mathabathe and Potgieter (2017) point out, coding MR involves inference. Thus, in different contexts, different criteria for MR can be set. Indeed, researchers have identified that these issues lead to difficulty of generalising research findings (see Panadero \& Järvelä, 2015; Schoor et al., 2015; Volet et al., 2009b).

From a theoretical perspective, contextual variables are often considered in isolation. A contextual variable might be participants' ages such as studies with very young children (e.g., Whitebread et al., 2009) or university students (e.g., Järvelä et al., 2013; Malmberg et al., 2015). Another contextual variable might be competence level (see Panadero \& Järvelä, 2015), addressed by including participants of various ability levels (e.g., Grau \& Whitebread, 2012; Janssen et al., 2007; Rogat \& Adams-Wiggins, 2014), examining groups with higher and lower performance (e.g., Schoor \& Bannert, 2012), or simply, high-achievers (Iiskala et al., 2011). A third contextual variable is disciplinary subjects such as science (Grau \& Whitebread, 2012; Rogat \& Adams-Wiggins, 2014; Zheng, Xing, \& Zhu, 2019), engineering (Nguyen et al., 2021), mathematics (Iiskala et al., 2011), statistics (Schoor \& Bannert, 2012), medicine (Lajoie \& Lu, 2012), education (Järvelä et al., 2013), or history (Janssen et al., 2007). In summary, contextual variables such as age (e.g., Vukman, 2005), 
academic level (e.g., Veenman \& Elshout, 1999) and discipline (e.g., Dori, Mevarech, \& Baker, 2018) have been suggested to influence activation of MR in learning.

Furthermore, other characteristics related to learning activity within the context, such as task characteristics and students' prior knowledge or expertise, also contribute to the manifestation of MR. For example, the contextual characteristics of a task are linked to the context in which the task is embedded. Features of the task, including familiarity or complexity, may impact students' MR. Unfamiliar tasks have been shown to trigger questioning, thinking, and reasoning, and familiar tasks more cumulative reasoning (Sockalingam \& Schmidt, 2013). In collaborative learning, complex and meaningful tasks, in turn, have been found to provide opportunities to collaborate, thus promoting regulation of collaborative learning (DiDonato, 2013). Thus, more complex problems have been shown to trigger more SSMR focusing on high-level cognitive activity than easier tasks (Iiskala et al., 2011).

Students' expertise is similarly related to context. For example, Khosa and Volet (2014) found that a group of veterinary students whose outcome performance was closest to that of the experts metacognitively regulated more co-construction of knowledge (i.e. focus on high-level cognitive activity) than the least successful group. This finding is consistent with other evidence that associates development of expertise with metacognitive skill (Veenman $\&$ Elshout, 1999). However, this association is not always straightforward. For example, Boshuizen and Schmidt (2008) revealed that experts in a medical context displayed the least regulation of their problem solving, presumably because of their professional fluency. Hence, the role and amount of MR displayed by experts depends on context-related task demands. Similarly, Malmberg, Järvelä and Kirschner (2014) showed that more successful outcome students in elementary school science thought carefully about how to proceed in more complex tasks and, as a result, actually used fewer strategies than less successful students.

Taken together, and in line with Järvenoja et al. (2015), contextual variables (age, academic level, discipline) and characteristics of learning activity (task characteristics, student expertise) are seen to contribute to the learning processes and the ways how MR is activated in those processes. These features are interrelated and linked within a collaborative learning context where MR occurs (see Järvenoja et al., 2015). Thus, in the present study, we adopted a holistic, situative perspective of context, positing that a learner's behavior within the collaborative group is inseparable from the social context in which the learning takes place (Engeström, 2001; Greeno, 2006; Johri, Olds, \& O'Connor, 2014), including the social processes (e.g., the interactions between student and instructor) complete with their own set of rules (e.g., classroom expectations, academic policies). Of course, the social processes and rules are influenced by the broader cultural norms in which the collaborative learning takes place (Wenger, McDermott and Snyder 2002). While characterization of such cultural norms is beyond the scope of this study, we used contexts in three countries on different continents as a proxy for varying cultural norms. Thus while contextual characteristics such as academic level, disciplinary subject, and national culture can contribute to context, it is in their plurality where the learning and regulation occur (i.e. high school science in Finland, university veterinary science in Australia, and university engineering in the United States).

In light of the research cited above, we believe that understanding MR in collaborative learning can be advanced through investigations of MR in diverse learning contexts, with operationalisation of MR and analytical methods that are consistently and rigorously the same. This need motivated the present study. 


\section{Aim of the study and research questions}

The overall aim of this exploratory study was to characterize the extent to which less and more successful outcome groups used MR processes to guide their learning in challenging science tasks. Specifically, we systematically investigated MR displayed by the groups in terms of different forms and foci of MR in three diverse collaborative learning contexts. Another aim was to validate a common theoretical and methodological approach. Correspondingly, we sought to study three science learning contexts that were diverse. We selected three contexts that differed in disciplinary subject (general science, veterinary medicine, engineering), academic level (high school, university), and national culture (Finland, Australia, United States), as these would provide sites where the learning contexts inevitably vary.

Due to the scarcity and fragmented nature of research on MR's forms and foci across contexts, hypotheses were not set; rather we asked the following research questions:

RQ1 Forms of MR: in each of three diverse contexts, how do forms of MR differ in the less and more successful outcome groups?

RQ2 Foci of MR: in each of three diverse contexts, what differences are evident in the foci of MR in the less and more successful outcome groups?

RQ3 Forms $\times$ Foci of MR: in each of three diverse contexts, what is the interplay of the social forms (including MOR and SSMR) and foci of MR in the less and more successful outcome groups?

\section{Method}

\section{Participants, sampling and collaborative learning contexts}

The present study consists of datasets from three diverse collaborative learning contexts: 2nd-year senior high school, advanced general science in Finland; 2nd-year university, Bachelor of Science veterinary medicine in Australia; and 4th-year university, Bachelor of Science engineering in the United States. Two groups were studied from each context, one of lower quality outcome (less successful) and one of higher quality (more successful). Video- or audio-recorded collaborative learning processes of the six selected groups were analysed. In the current section, first, the common sampling method is described. Next, each context is described including a brief description of that context, selection of the less and more successful outcome groups and the segments for in-depth analysis.

First, from each context, the less and the more successful outcome groups were selected from a larger sample of groups based on the group's collective outcome. Quality of the group's collective outcome-rather than individual student outcomes-was used as the selection criterion for the analysis since research literature on collaboration (e.g. Dillenbourg, 1999; Roschelle \& Teasley, 1995) regards a groups' shared goal as central to collaboration. In the present study, valuable collaborative learning was seen as meaning-making and co-construction of knowledge so that learners aim to build a common understanding on each others' view (Hargreaves, 2007; Khosa \& Volet, 2014) towards a common goal (Dillenbourg, 1999; Roschelle \& Teasley, 1995). All tasks in the present study used this principle, that is, students worked towards a single shared production of the problem. Furthermore, the manifestation of social forms of MR, especially SSMR, presupposes the existence of a group's common goal (see e.g., Hadwin \& Oshige, 2011; Iiskala et al., 2011; 
Schoor et al., 2015). Hence, groups' collective outcome reflected the desired learning as has been suggested in valid assessment (see Dillenbourg, 1999; Hargreaves, 2007).

Second, the selected groups' collaborative learning processes were analysed in depth. In all contexts, small groups of students completed a collaborative science learning activity, designed as part of their respective course curricula, whose goal was to produce a tangible outcome as a group. All three activities were designed to create opportunities for students to engage productively in the task to gain a deeper understanding of scientific concepts and practices, as well as to present students with new challenges (Koretsky et al., 2019; cf., Engle, 2012). This design aligns with the recommendation from early metacognition scholars that research on MR should be undertaken in 'real world' contexts in order to maximise ecological validity (Brown, 1978). A summary of the key features of each context including a description of the group work (see "Appendix 1") and groups (see "Appendix 2") is provided (see also Koretsky et al., 2019).

In each context, segments of the chosen groups' collaborative learning processes were selected by experts with both education and content knowledge (biology and chemistry, veterinary science, and engineering). For each group, two distinct, meaningful, and selfcontained interaction segments (of approximately 10-16 min) were identified to strengthen the validity of the study (e.g., Grau \& Whitebread, 2012). Segments were selected based on two criteria: First, they were crucial to task performance and completion. For each context, segment 1 focused on planning and scoping and segment 2 on generating a communications artifact. Context segments included: planning the scientific research (segment 1) and presenting conclusions from the experiment (segment 2) for Finnish high school science students; generating learning objectives (segment 1) and constructing a concept map (segment 2) for 2nd-year Australian university veterinary science; and scoping a problem (segment 1) and preparing a design memorandum (segment 2) for 4th-year American university engineering groups. Second, answers were not straightforward but demanded students' collaboration. Segments, rather than the entire interactive processes, were analysed, which ensured that the selected segment lengths were similar across groups, and made systematic and in-depth data coding manageable. The selection of segments for in-depth analysis was also supported by the finding of no statistical differences in cognitive activity between segments for each group where the same data as used in this study was analysed from a cognitive perspective (see Koretsky et al., 2019).

Participation was voluntary, and signed consent for recording of group work was provided by the students (or legal guardians of students under 18 years of age). Data were anonymised and all material was stored according to the regulations of each country. Ethical principles were stringently followed, in accordance with national guidelines (Finland, Australia, and the United States).

\section{Context 1: Senior high school general science in Finland}

Small groups of students $\left(N_{\text {students }}=120\right)$ between the ages of 16 and 18 worked on advanced-level science content in a virtual collaborative learning environment integrating biology and chemistry. During the three sessions ranging from 75 to $95 \mathrm{~min}$, the groups $\left(N_{\text {groups }}=39\right)$ conducted a scientific experiment according to the phases of scientific research: (1) Planning, including generation of a hypothesis and experiment, (2) Experimentation, and (3) Conclusions, including analysing results based on the experiment and preparing a joint presentation. 
The group's collective outcome was a joint presentation that was assessed on a scale of $1-6$ by experts in biology and chemistry based on quality of scientific language, hypotheses, research plan, and conclusions. The less successful outcome group's collective presentation was given a score of 1, and the more successful outcome group's presentation a score of 5 . The selected groups received extreme scores out of 39 groups of 2-4 students and all students were present in all sessions. Both selected groups consisted of three female students.

Two video-recorded interaction segments of the overall task from the phases of scientific research 1 (Planning) and 3 (Conclusions) were selected for analysis from the both the selected groups.

\section{Context 2: University 2nd-year veterinary science in Australia}

Collaborative case-based clinical assignments were part of a mandatory second year physiology unit. The age range of the students $\left(N_{\text {students }}=63\right)$ varied mostly between 19 and 25 years. Students working in small groups $\left(N_{\text {groups }}=11\right)$ were tasked with setting their group's key learning objectives related to randomly assigned real-life clinical cases, researching case content, constructing a case concept map based on their research, and producing a class presentation. Each group had two scheduled meetings with the teacher to provide guidance, and were otherwise free to meet outside normal class time as often as they needed to complete their work.

The groups' collective outcomes were concept maps assessed through a calculation of percentage of agreement with experts' maps. Selected concepts and links between them (associative or causal) were assessed. The less successful outcome group's percentage agreement with the experts' map was $56 \%$ and the more successful outcome group's $92 \%$. The selected groups received extreme scores out of 11 groups of 5-6 students. The selected less successful outcome group consisted of five females and one male, and the more successful outcome group was made up of four females and one male student.

Data for this context were video recordings of the groups' interactions for two interaction segments of the overall task from two phases (generating learning objectives and constructing a concept map of a clinical case).

\section{Context 3: University 4th-year engineering in the United States}

The collaborative assignment the students $\left(N_{\text {students }}=64\right)$ were tasked with, the Virtual Chemical Vapor Deposition (VCVD) process, is aimed at forming a bridge between university studies and industry through the adoption of processes and objectives akin to professional practice. The age range varied mostly between 21 and 25 years. The student groups $\left(N_{\text {groups }}=22\right)$ had to develop a "recipe" of input parameters for an industrial reactor, taking into consideration constraints typical to real-life settings. Each group had three scheduled project meetings with the project supervisor, and were free to meet as much as they needed to complete the work.

As the group's collective outcome, the grade given by the project supervisor of the group's memorandum was on a scale of $0-10$. The less successful outcome group received a score of 8 and the more successful outcome group a score of 10 . This was 
the largest difference in grade within the cohort of available data from 22 groups of 2-3 students. Both the less and the more successful outcome groups consisted of two males and one female.

Audio recorded meetings during which groups undertook their initial information gathering and problem scoping, and prepared their design memorandums, were analysed.

\section{Data for coding cognitive activity and MR}

Data for this study were transcribed video or audio recordings of the selected less and more successful outcome groups' interactions for two interaction segments of the overall task.

\section{Coding cognitive activity and MR}

Across learning contexts, the groups' verbal interactions formed the basis of the analyses, but were complemented by non-verbal communication (available in high school and veterinary data), such as directions of gazes. First, cognitive activity (see Koretsky et al., 2019) was analysed (off-task, low-level, and high-level) based on Volet, Summers and Thurman (2009a) and Khosa and Volet (2014). Second, MR was analysed based on Iiskala et al., (2004, 2011, 2015) and Volet et al. (2017) and further developed in this study in terms of no MR, VMSR, IMR, MOR, and SSMR. The coding categories, including examples from each context, are described in Table 1 (cognitive activity) and Table 2 (MR). In cognitive activity and MR analysis, each "turn," a student's speech act that continued until another student began to speak, was coded. To code a turn as SSMR, at least two interconnected turns had to be coded as such (see Table 2).

\section{Inter-rater reliability}

Cognitive activity and MR were coded by two researchers who acted as interraters across all contexts. To increase validity, the coders were different scholars than those who selected the less and the more successful outcome groups and the segments to be coded, and therefore did not know which group had the less or more successful outcome. In each case, the principal coder was a native speaker of either American or Australian English for the university contexts, or Finnish for the high school context, in which case all data for coding was translated into English for the purpose of inter-rating. All coders had detailed transcriptions of interactions and access to video/audio-recordings. After the principal coder had completed the coding in a particular context, the interrater assessed a minimum of $20 \%(20-26 \%)$ of selected data from each context for the less and more successful outcome groups and for both segments. Inter-rated reliability was assessed in both foci of MR (lowor high-level cognitive activity) and different forms of MR (VMSR, IMR, MOR, SSMR) separately in each context. The values for the number of inter-rated turns, the agreement percentage, and Cohen's kappa in foci ("cognitive activity") and forms of MR ("MR") per context are shown in Table 3. Regarding both cognitive activity and MR, inter-rater reliability was at least substantial (see Landis \& Koch, 1977, p. 165). There were only minor disagreements, the most common being between MOR and SSMR, which were resolved through discussion. 


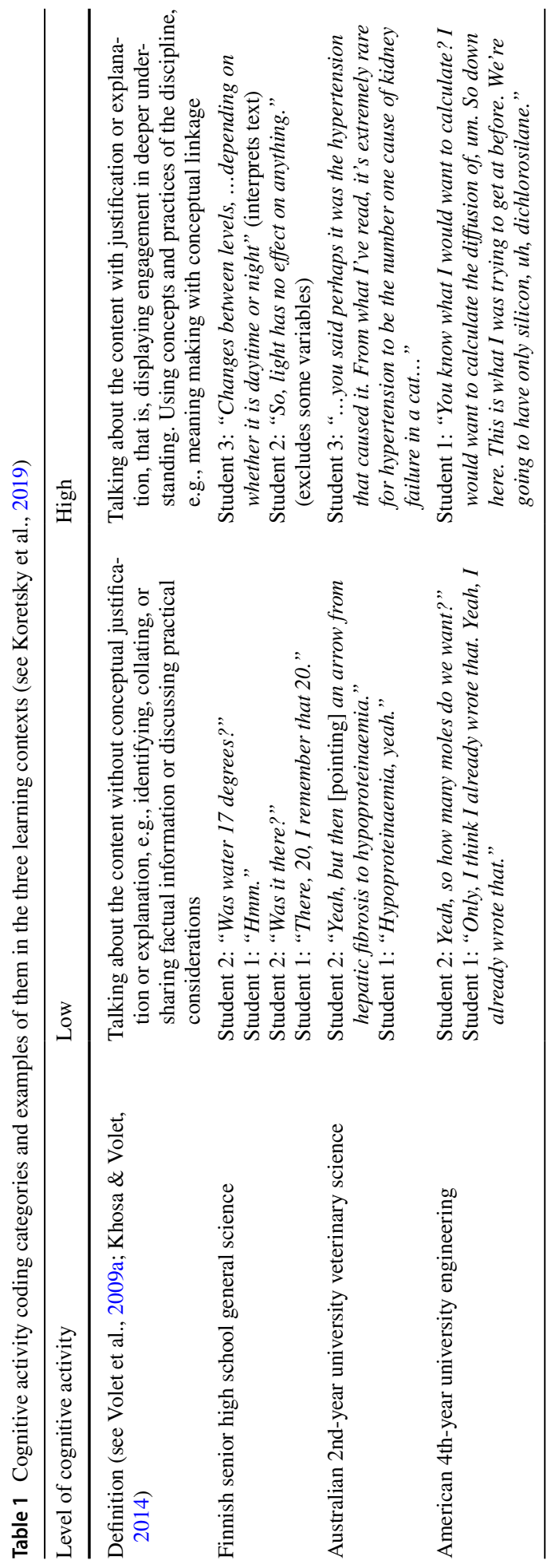




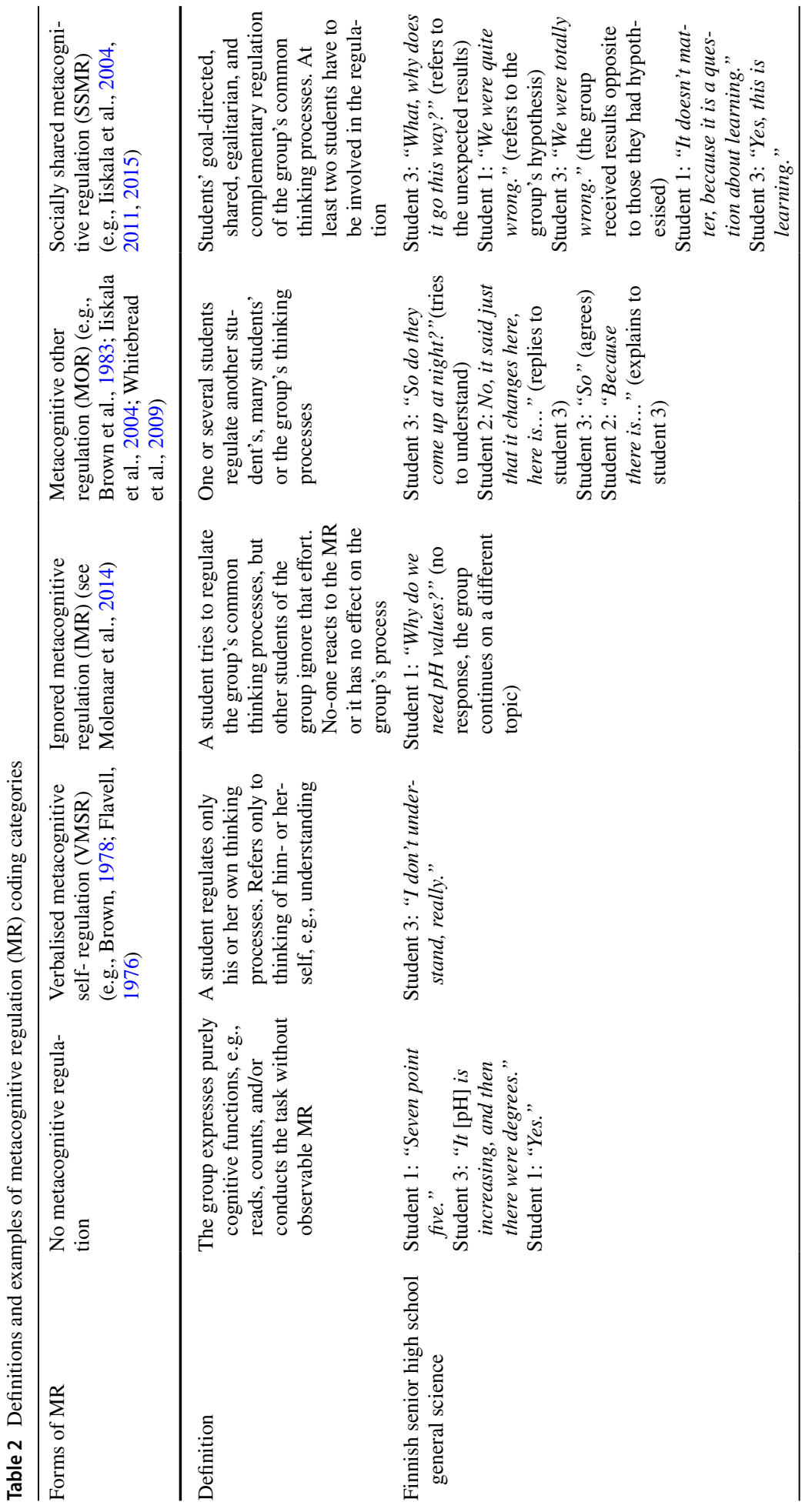




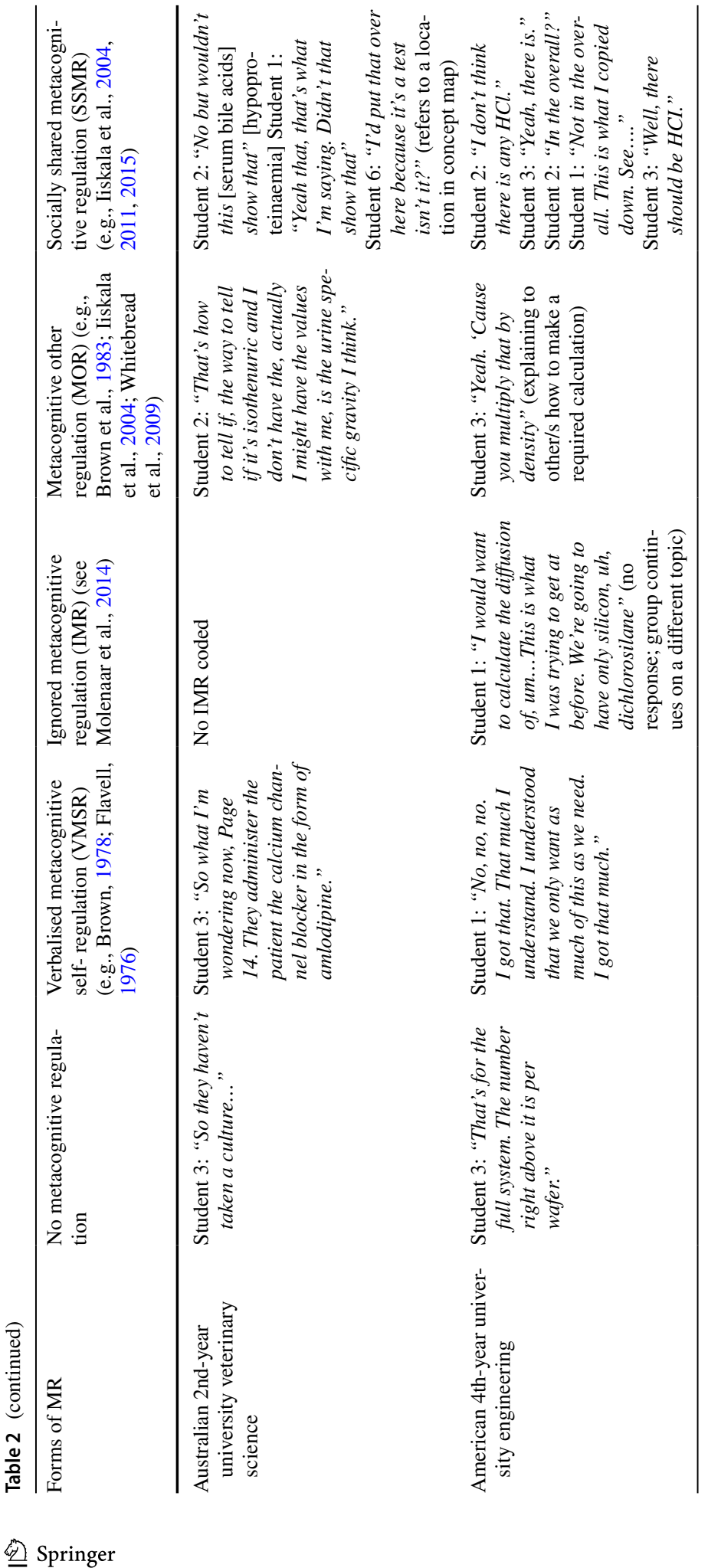




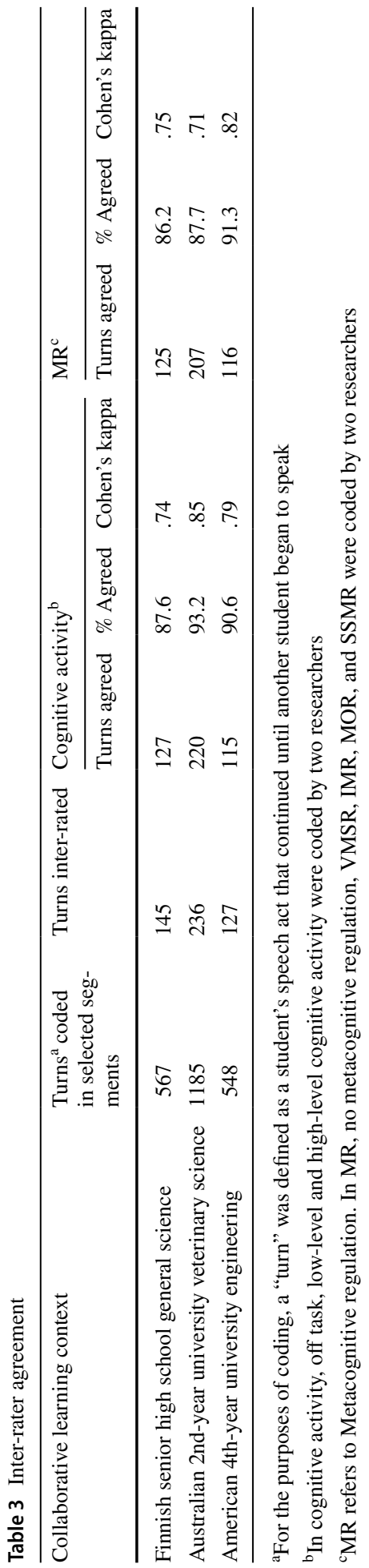


Table 4 Coded data: all data, all cognitive activity, and metacognitive regulation (MR) data in different learning contexts for less (LS) and more (MS) successful outcome groups

\begin{tabular}{|c|c|c|c|c|c|c|c|}
\hline \multirow{2}{*}{$\begin{array}{l}\text { Context } \\
\text { Group }\end{array}$} & \multicolumn{2}{|c|}{$\begin{array}{l}\text { Finnish } \\
\text { senior high } \\
\text { school gen- } \\
\text { eral science }\end{array}$} & \multicolumn{2}{|c|}{$\begin{array}{l}\text { Australian } \\
\text { 2nd-year } \\
\text { university } \\
\text { veterinary } \\
\text { science }\end{array}$} & \multicolumn{2}{|c|}{$\begin{array}{l}\text { American } \\
\text { 4th-year } \\
\text { university } \\
\text { engineering }\end{array}$} & \multirow[t]{2}{*}{ Total } \\
\hline & LS & MS & LS & MS & LS & MS & \\
\hline \multicolumn{8}{|l|}{ All coded data } \\
\hline No. of turns & 303 & 239 & 519 & 552 & 275 & 221 & 2108 \\
\hline \multicolumn{8}{|l|}{$\begin{array}{l}\text { All turns of } \\
\text { cognitive } \\
\text { activity }\end{array}$} \\
\hline Low level & 273 & 175 & 469 & 356 & 139 & 152 & \\
\hline High level & 30 & 64 & 50 & 196 & 136 & 69 & \\
\hline \multicolumn{8}{|l|}{ All MR data } \\
\hline $\mathrm{f}^{\mathrm{a}}$ & 61 & 79 & 102 & 154 & 112 & 75 & \\
\hline$\%$ of all data ${ }^{b}$ & 20.1 & 33.1 & 19.7 & 27.9 & 40.7 & 33.9 & \\
\hline
\end{tabular}

${ }^{\mathrm{a}}$ Frequencies of MR turns of all coded data

${ }^{b}$ Percentages of MR of all coded data

\section{Data for analysis}

For analysis, off-task behaviour was omitted, including 25 turns (4.4\%) out of 567 turns in high school science, $114(9.6 \%)$ out of 1185 turns in 2nd-year university veterinary science, and $52(9.5 \%)$ out of 548 turns in 4th-year university engineering. Table 4 presents the total number of coded turns, total number of turns at the low- and high-cognitive activity level, and the number of turns coded with MR and the corresponding percentage of MR relative to total turns for less and more successful outcome groups in all three contexts. Since the students in the Finnish high school science and the university engineering groups in the American context also interacted with a computer, the number of verbal turns is lower than for the veterinary groups.

The focus of MR was classified according to cognitive activity (see Tables 1,2). The focus of MR was categorized as high if the turn was classified as high in the cognitive activity coding. Conversely, the focus of MR was classified as low for turns classified as low in the cognitive activity coding. For example, in the Finnish senior high school general science setting, the focus of VMSR was classified as high for the turn "I don't really understand" which was classified as high in cognitive activity coding (in the broader transcript, this student refers explicitly to understanding the conceptual issue at hand) and as VSMR in MR coding. As another example from the same context, the student's question of meaning making such as "Why do we need pH values?" was classified as high level cognitive activity and as IMR (no response, in which case the turn remained as an individual's effort to regulate) in which case the focus of IMR was high. Further, MOR's focus, for example, on low level cognitive activity appeared when the student regulated another student's thinking process in the American 4thyear university engineering context: "Yeah. 'Cause you multiply that by density." In the example, factual information was shared as an indication of low level cognitive 
activity. Finally, SSMR's focus is exemplified with Australian 2nd-year university veterinary science context among three students' regulation as follows: Student 2: "No but wouldn't this [serum bile acids] show that" (focus high as meaning making with conceptual linkage), Student 1: “... Didn't that show that" (focus still high), Student 6: "I'd put that over here because it's a test isn't it?" (Focus low as turn focusing on academic deliverable). Thus, in SSMR the focus could change between high and low cognitive level from turn to turn.

\section{Results}

The MR displayed by less and more successful outcome groups, in terms of MR's forms and foci, was examined in the three diverse collaborative learning contexts. Concerning RQ1 and RQ2, percentages and frequencies of MR results are presented in Table 5. In RQ3 qualitative illustrations are provided.

\section{Forms of MR: Differences in forms of MR in the less and more successful outcome groups}

Specific forms of MR were divided into two categories: social (including MOR and SSMR) and individual (including IMR and VMSR; see details and examples, Table 2).

Table 5 Forms, foci, and forms $\times$ foci of MR in the different learning contexts for the less (LS) and more (MS) successful outcome groups

\begin{tabular}{|c|c|c|c|c|c|c|c|c|c|c|c|c|}
\hline \multirow{2}{*}{$\begin{array}{l}\text { Context } \\
\text { Group }\end{array}$} & \multicolumn{2}{|c|}{$\begin{array}{l}\text { Finnish } \\
\text { senior high } \\
\text { school } \\
\text { general } \\
\text { science }\end{array}$} & \multicolumn{2}{|c|}{$\begin{array}{l}\text { Australian } \\
\text { 2nd-year } \\
\text { university } \\
\text { veterinary } \\
\text { science }\end{array}$} & \multicolumn{2}{|c|}{$\begin{array}{l}\text { American } \\
\text { 4th-year } \\
\text { university } \\
\text { engineering }\end{array}$} & \multicolumn{2}{|c|}{$\begin{array}{l}\text { Finnish } \\
\text { senior high } \\
\text { school gen- } \\
\text { eral science }\end{array}$} & \multicolumn{2}{|c|}{$\begin{array}{l}\text { Australian } \\
2 \text { nd-year } \\
\text { university } \\
\text { veterinary } \\
\text { science }\end{array}$} & \multicolumn{2}{|c|}{$\begin{array}{l}\text { American } \\
\text { 4th-year } \\
\text { university } \\
\text { engineering }\end{array}$} \\
\hline & LS & MS & LS & MS & LS & MS & LS & MS & LS & MS & LS & MS \\
\hline All MR turns & 61 & 79 & 102 & 154 & 112 & 75 & & & & & & \\
\hline Forms of MR & \multicolumn{6}{|c|}{ Turns of MR } & \multicolumn{6}{|c|}{$\begin{array}{l}\text { Percentage of forms of MR out of all } \\
\text { MR turns }\end{array}$} \\
\hline SSMR & 15 & 30 & 94 & 141 & 99 & 64 & 24.6 & 38.0 & 92.1 & 91.6 & 88.4 & 85.3 \\
\hline MOR & 33 & 46 & 2 & 7 & 10 & 11 & 54.1 & 58.2 & 1.9 & 4.5 & 8.9 & 14.7 \\
\hline IMR & 13 & 2 & 0 & 0 & 2 & 0 & 21.3 & 2.5 & 0 & 0 & 1.8 & 0 \\
\hline VMSR & 0 & 1 & 6 & 6 & 1 & 0 & 0 & 1.3 & 5.9 & 3.9 & 0.9 & 0 \\
\hline Foci of MR & \multicolumn{6}{|c|}{ Turns of MR } & \multicolumn{6}{|c|}{$\begin{array}{l}\text { Percentage of MR of high- and low-level } \\
\text { cognitive activity out of all MR turns }\end{array}$} \\
\hline Low level & 41 & 25 & 83 & 48 & 30 & 37 & 67.2 & 31.6 & 81.4 & 31.2 & 26.8 & 49.3 \\
\hline High level & 20 & 54 & 19 & 106 & 82 & 38 & 32.8 & 68.4 & 18.6 & 68.8 & 73.2 & 50.7 \\
\hline Form $\times$ Foci of MR & \multicolumn{6}{|c|}{ Turns of MR } & \multicolumn{6}{|c|}{$\begin{array}{l}\text { Percentage of social MR on high and low } \\
\text { cognitive levels out of all MR turns }\end{array}$} \\
\hline SSMR-Low & 9 & 0 & 77 & 41 & 28 & 35 & 14.7 & 0 & 75.5 & 26.6 & 25.0 & 46.7 \\
\hline SSMR-High & 6 & 30 & 17 & 100 & 71 & 29 & 9.9 & 37.9 & 16.7 & 64.9 & 63.4 & 38.7 \\
\hline MOR-Low & 25 & 23 & 1 & 2 & 1 & 2 & 40.9 & 29.1 & 1.3 & 1.3 & 0.9 & 2.7 \\
\hline MOR-High & 8 & 23 & 1 & 5 & 9 & 9 & 13.1 & 29.1 & 1.3 & 3.2 & 8.0 & 12.0 \\
\hline
\end{tabular}


Overall, both less and more successful outcome groups manifested more social than individual forms of MR in all three contexts (Table 5, "Forms of MR"). MOR comprised the majority of social MR turns of both the less and more successful outcome high school groups. Alternatively, SSMR comprised the majority of social MR of both less and more successful outcome groups in both 2nd-year Australian university veterinary science and 4th-year American university engineering groups. The individual MR turns for Finnish high school science students were mostly IMR, especially concerning the less successful outcome group; for 2nd-year Australian university veterinary science students VMSR in both less and more successful outcome groups; and with very little of either (IMR or VMSR) among 4th-year less successful outcome American university engineering group and totally absent among the more successful outcome group.

\section{Foci of MR: Differences in the foci of MR in the less and more successful outcome groups}

Groups' cognitive activity was evident at two levels (low and high), which distinguished students' depth of engagement with the scientific content, measured, for example, through extent of justifications or explanations (see Table 1). Table 5 ("Foci of MR") shows the number of MR turns of low- and high-level cognitive activity for each context. Compared to more successful outcome groups, the MR of less successful outcome groups of Finnish high school science and Australian university veterinary students was focused more on low-level cognitive activity. The opposite was true for the American university engineering students, with the less successful outcome group showing evidence of more high-level cognitive activity MR, and the more successful outcome group equally regulating both high and low levels of cognitive activity.

\section{Forms $\times$ foci of MR: The interplay between forms and foci of social MR in the less and more successful outcome groups: qualitative examples illustrating differences in actual group interactions}

Table 5 ("Form $\times$ Foci of MR") presents the frequency of each form of social MR (SSMR and MOR) and the percentage relative to total MR turns for each context at the same level of cognitive activity (i.e. focus of MR) and the group's outcome quality. We do not report individual MR values because these values were relatively small (see Table 5). As can be seen in Table 5, the Finnish high school science students showed both MOR and SSMR, with the less successful outcome group exhibiting more MOR and SSMR of low-level cognitive activity, and the more successful outcome group a similar amount of MOR of high- and low-level cognitive activity focusing all SSMR on high-level cognitive activity. In contrast, both the Australian university veterinary science and American university engineering student groups showed SSMR predominantly, but SSMR in terms of foci differed in a meaningful way. The less and more successful outcome groups of veterinary science students had distinctively different foci of MR, the less successful outcome group regulating their low-level cognitive activity more and the more successful outcome group their high-level cognitive activity 
more. Interestingly, an opposite, though less striking manifestation of SSMR's foci was observed for the engineering students.

The findings regarding the interplay of forms and foci of MR are illustrated in qualitative examples of students' verbal interactions. The examples contrast how social MR manifested in students' verbal interactions among the less and more successful outcome groups in each context. The examples are taken from the same segments of the groups' processes in which case it is possible to mirror the less and more successful outcome groups with each other, especially, how the groups metacognitively steer their collaborative learning process. This analysis provides deeper insights into the interplay of MR's forms and foci among the different outcome groups and contexts.

\section{Senior high school general science in Finland}

As shown in the above results, the Finnish high school science students' social MR was manifested both in a form of MOR or SSMR in both groups. However, important qualitative differences occurred concerning the longer MR processes. Although the less successfully performing group's MOR was typically at the high cognitive activity level, it was intertwined with SSMR turns and fluctuated between high and low cognitive activity as the following typical excerpts demonstrate.

In the beginning, when trying to form hypotheses, the less successfully performing group focused SSMR on the high cognitive activity level, and the discussion shows how the students tried to understand the relationship between $\mathrm{pH}$ and temperature: "What do we assume?" As a reaction to this question, another student raised the issue of that relationship: "I don't know because there was inconsistency that first, it was said that pH effects but then, that temperature more because if temperature was low..." then continued thinking and after a while, said, "...it was noted that when it $[\mathrm{pH}]$ was low, it was depending on temperature." Another student then joined the thinking process: "Hmm, if it is that $\mathrm{pH}$ and temperature so maybe temperature more because..." However, the focus on high-level cognitive activity was not sustained, and the group resumed lowlevel metacognitive other regulation (MOR). Upon reaching an impasse, the group typically drifted into regulating low cognitive activity and single issues, and regulating factual information (MOR), as indicated by the question, "How did it go, was it, how, when was more?" and its reply, "Twenty degrees was negative." As a consequence, the group demonstrated no clear picture of $\mathrm{pH}$ either in the form of a written hypothesis or conclusion. Throughout the learning activity, the group often regulated their lack of knowing, but without leading to the successful co-construction of knowledge that had characterised the group's SSMR. Less powerful MR in this group was further highlighted with their IMR. For example, when one student asked, "Why do we need pH values?" nobody responded; IMR was not helpful to the group's learning processes.

A different picture emerged from the more successful outcome group. Similar to the less successful outcome group, this group also tried to interpret the given information on which to build their hypotheses, and admitted to not knowing the importance of $\mathrm{pH}$. However, unlike their less successfully performing counterparts, students in the more successful outcome group reacted to their initial admission of uncertainty and lack of knowing by attempting to co-construct why $\mathrm{pH}$ could be important (SSMR), as follows: "Why is pH important?" followed by "so pH is, I don't know," and "But what things are included in it $[\mathrm{pH}]$," then moving to possible explanations such as, "It has an effect on which [organisms] can live there [in the Baltic Sea], doesn't it?" Throughout the 
discussion, fluctuating between SSMR and MOR, different students participated in regulation and expressed it by consistently mirroring what they knew, for example: "We know what it means so we can proceed" and "What do we know about..." or what they did not need to know: "We don't need to know." At the end of the learning activity, the group compared its hypothesis to the findings of the experiment: "So, our hypothesis one was wrong because..." The group did not just state that their hypotheses were wrong, but also wanted to know why: “...why does it go this way?" indicating highlevel cognitive activity once again.

In sum, the qualitative examples of the Finnish high school science student groups show how similar kinds of questions and problems (such as "Why is pH important?") led to different manifestation of MR. The most significant difference is that the less successful outcome group's social MR only briefly focused on high-level cognitive activity, flitting from one issue to the next. The more successful outcome group's MR focused instead at a high cognitive level for longer periods, social MR being present throughout the process (e.g., MR focus during 16 consecutive turns on high-level cognitive activity turns vs. 3 turns maximum in the less successfully performing quality outcome group).

\section{University 2nd year veterinary science in Australia}

As reported above, both the less and more successful outcome veterinary student groups' social MR was dominated by SSMR, with minimal MOR. Groups were clearly differentiated, however, by the foci of their respective SSMR. Typically, the less successful outcome group jointly regulated procedural matters and low-level cognitive activity, while the more successful outcome group regulated its high-level cognitive activity aimed at achieving a collective, deep understanding of its case.

The difference in foci of their social MR was evident in the groups' first meeting, when they examined the file notes of their respective 'real-life' cases, in order to generate their learning objectives and determine what to research. In the less successful outcome group, in addition to a procedural focus on what they would need for the presentation of their case, there was more 'ready agreement' within their SSMR. For example, as they perused the case notes: "Increased bile acids cos the liver's not detoxifying properly, same with, oh but low urea, low protein," was responded to with "Yeah we need to look into that I think... Why the urea would be low, and with the Ascites," with a third student adding, "Also, we need to learn...maybe although we don't talk about the whole thing in the presentation, maybe that is something... need to understand," to which the group readily agreed.

In contrast, at the same stage of the process, the more successful outcome group did not talk about the class presentation, but focused on understanding the case. This is exemplified in the following SSMR with a high-level focus, where they too, upon reading the case notes, identified phenomena to 'look into': “Yeah. It's $7 \mathrm{~g}$ per litre so this is where it's getting really confusing is because an increase in protein without there being some kind of haemolyser... indicates that there is a decrease in water because your concentrations have increased. But if there's a decrease in water how did you get hypertension? That's what we've gotta..." with which two members briefly agree, with another responding: "Yeah that's what I was thinking. Yeah does more protein just mean more water?" A fifth student added, "So perhaps we need to look into hypertension."

The recurrence of similar interaction emerged in the two groups' concept map activity, when they considered which of the provided concept cards could be 'wildcards,' irrelevant to their case. In the less successful outcome group, after two students agreed that "dogfight 
can go off...", another student challenged this by saying, "But dog fight could be a cause." While one student agreed, the original student countered, "But it's not in our case we don't know what the cause is." Two other students agreed, and the original challenger closed the discussion, saying, "Just put it to the side for now." This excerpt shows a brief SSMR at a high level triggered by a challenge, but ending quickly after the counter challenge, and a decision made without discussion. In contrast, the more successful outcome group typically engaged in long episodes of SSMR at a high level throughout the activity, with members constantly responding to each other's input. It started with the consideration of possible 'wildcards': "Weight loss and anorexia were not factors in this case," responded to with, "but they can be factors of..." and another student challenging: "But can they be factors?" which led to further speculation, such as: "Maybe they're factors of hyperthyroidism" and "not the Anorexia but the weight loss. Anorexia." Many SSMRs in this group involved questioning and argumentation. For example: "Azotaemia would cause weight loss?" was responded to with, "yeah" followed by "Nooo" (emphatically drawn-out); then, "why not?" and in response, "Because the Azotaemia doesn't like burn up calories the Azotaemia just makes them sick" and so it continued until they reached consensus, and only then proceeded with the linkage of cards.

\section{University 4th year engineering in the United States}

Like the Australian university veterinary science students, the American university engineering students displayed predominantly SSMR, and IMR or VMSR minimally. Unlike in the veterinary science student groups, though, there were some instances of MOR, mostly focusing on high-level activity and minimally directive. For example, in the more successful outcome group, one student walked the group through flow rate calculations: "We, $I$ calculated the volume of silicon nitride that will be deposited..." In the less successful outcome group, MOR came from several members. For example: "And then is that with reference are we doing an average volumetric flow rate or an average of other values?" was responded to with "I mean, we're not. I'm just using... I don't know. We just assume that this would be... good but yeah we definitely gonna have to do..." Both groups' MOR was less procedurally directive, and mostly in the high cognitive realm, as the groups questioned, explained, and justified their calculations, which is further illustrated in this example from the less successful outcome group: "I was saying that uh I'm have some concern for is the um, estimated reaction rate because those are based off of the different parameters that uh like an average of their parameters is that within the parameters that we're doing?"

Early in the process, and for both MOR and SSMR forms of social MR, there was evidence in students' interactions of frequent efforts to reach collective understanding within the less successful outcome group, and of a level of acceptance of each member's contributory knowledge within the more successful outcome group, which seemed to reduce the need for SSMR.

The following SSMR example from the less successful outcome group illustrates a debate based on a fundamental assumption about how to approach one of the chemical reactions - whether to assume it occurs instantaneously or to calculate a rate constantwith one member invoking their interpretation of the information provided by the course instructor: "If $K 2$ is much faster than Kl" was responded to with "So that's something we need to calculate," and a third student asking, "K2? Where is K2?" A student then referred to the instructor as a source of authority, saying, "No, he said that, he told us in class that it 
was, the second reaction is near a hundred (percent) complete. He said we could calculate it, but it's he pretty much told us we didn't have to," which was responded to with, "Yeah but the question is how fast it happens," to which the previous student added: "No, I think he was talking about whether or not the reaction went to completion." This episode proceeded for six more turns of SSMR, as the group collectively interacted with scientific content and tried to develop a shared understanding that would help them agree on a solution.

In contrast, in the more successful outcome group, there was evidence of smooth social MR of a collective understanding early in the process as information was gathered, and a sense of building efficiently on one another's contributions. This point is illustrated in the following SSMR episode: "Geez. 0.2 Torr" was responded to by "That's really low" then "Stress. Is that something we have to worry about?" to which another student responded, "Uh, I don't think so. I think we'll be fine" which is agreed upon with some further thinking: "Hmm. Alright. Hmm. Yeah, when-we're gonna have not uniform temperature anyways, so..."

In sum, the American university engineering students' social MR was characterised by a dominance of SSMR in both less and more successful outcome groups, but to a greater extent in the less successful outcome group as they were working to make sense of the complex task. In the more successful outcome group, students were typically able to build on each other's seemingly better understanding of the underlying concepts, with consequently less need to engage in as much SSMR.

\section{Discussion}

This study examined the extent to which less and more successful outcome groups use MR processes, particularly forms and foci, to guide their learning during challenging scientific tasks. The research design included three diverse collaborative learning contexts, across which we systematically applied the same conceptual and methodological approach. In all three contexts, the group tasks were designed using the same guiding principles in order to provide groups with the opportunity to form a deeper understanding of scientific concepts and practices (Engle, 2012; Koretsky et al., 2019). However, the contexts, as characterized by academic level, disciplinary subject, and national culture, all differed.

The first main contribution of this study was to reveal that MR, in terms of its form and foci, manifests differently in less and more successful outcome groups' learning processes in three diverse contexts. Previous research on the relationship between different forms and foci of MR and their relation to learning outcomes in a collaborative learning context is scarce. From its outset, the metacognition research tradition was based on the idea that the emergence of metacognition leads to successful learning outcomes (see Brown, 1978; Flavell, 1976). However, as the findings of the present study suggest, this idea does not completely pertain to collaborative learning where the concept of MR manifests as both individual (VMSR and IMR) and social (MOR and SSMR) processes (Efklides, 2008). Thus, the present study contributes to a better understanding of the interplay of MR, particularly its forms and foci, and learning outcome in collaborative learning. This understanding highlights the importance of context. The present study, therefore, provides initial insight into the role of context in studying MR in terms of its forms and foci in collaborative learning. 
The second main contribution was to demonstrate that a uniform conceptualisation of MR and related analytical tools can be successfully applied to examine different contexts of collaborative scientific learning. Since MR is typically studied in a single collaborative learning context, and different studies use different conceptualisations of MR (see Schoor et al., 2015), and a range of analytical tools (see Hadwin \& Oshige, 2011; Panadero \& Järvelä, 2015; Vauras, Volet, \& Iiskala, 2021), it is difficult to compare results and reach general conclusions. The present study partially addressed this challenge by using the same conceptualisation and analytical tools to reveal how MR and its forms and foci in collaborative learning manifest in diverse collaborative learning contexts. In this way, the study also aimed to address context in studying MR in collaborative learning (see Järvenoja et al., 2015; Molenaar et al., 2012). The present study illustrates that when the same conceptualizations and analytical tools are used, it is easier to evaluate the role of MR in diverse collaborative learning contexts.

\section{Forms and foci of metacognitive regulation (MR) in less and more successful outcome groups' collaborative learning}

Concerning RQ1, although all groups' processes included MR, differences between less and more successful outcome groups were found. As expected, given the collaborative nature of the science tasks, social forms of MR (including MOR and SSMR) were more prevalent than individual MR (including VMSR and IMR) in both outcome groups in all contexts. This finding aligns with previous research conducted in high school science (Zheng et al., 2019), university veterinary science (Khosa \& Volet, 2014) and university engineering (Nguyen et al., 2021).

Both less and more successful outcome Finnish high school science groups' regulation processes were characterised with MOR to a meaningful degree, and MOR was present more frequently than SSMR during low-level cognitive activity. Our qualitative illustrations show that unlike the more successful outcome group, MOR for the less successful outcome group enhanced regulation towards low-level cognitive activity, as also found by Mathabathe and Potgieter (2017). The less successful outcome group especially demonstrated IMR. This finding reveals lost opportunities for learning. Ignoring MR triggers, such as asking 'why' questions, do not support learning processes. Low cognitive level MOR or IMR did not emerge in any of the Australian university veterinary groups or the American university engineering university groups. Based on a holistic view, we do not assume and are not even able to argue that any single contextual feature alone could explain the findings. However, these results suggest, as a part of the explanation, a possible developmental influence as noted by other researchers (e.g. Vukman, 2005). Although we cannot make claims of developmental progression based on this exploratory study, our findings indicate this as an interesting research direction to pursue. If this conjecture was supported, it would offer a practical implication to provide more explicit support for cultivating the required competencies for effective joint regulation.

In the present study, we did not investigate socioemotional interactions, which could be related to the forms of MR that groups exhibited, such as in IMR. Other research has shown that co-occurrence of socioemotionally positive interactions and regulation support a meaningful collaborative learning process (e.g. Isohätälä, Näykki, \& Järvelä, 2020); this aspect warrants future investigation. In the present study, we also did not consider students' prior knowledge. However, differences in students prior knowledge could partly explain, for example, the emergence of MOR in the Finnish high school context. SSMR requires 
negotiating differences (see Iiskala et al., 2004, 2011; Järvelä et al., 2013) in prior knowledge which entails more social skill than the asymmetric interactions of MOR (Iiskala et al., 2004; Whitebread et al., 2009). Interestingly, although the group size in the Australian context was larger (5-6 students in each group) than in other contexts (generally 3 students), the Australian groups displayed only a minimum amount of IMR and MOR, indicating productive collaborative learning processes. However, previous research (e.g., Iiskala et al., 2015) has shown that students' participation varies within groups. Thus, it would be important to explore whether only some students participate in each episode of SSMR, and whether they are the same students in each episode.

Concerning RQ2, differences in the foci of MR processes for less and more successful outcome groups appeared between diverse learning contexts. The manifestation of MR for the Finnish high school science and Australian university veterinary science student groups resembled each other: The less successful outcome groups showed greater MR of low-level cognitive activity, and the more successful outcome groups greater MR of highlevel cognitive activity. This finding supports previous studies (Järvelä et al., 2013; Khosa \& Volet, 2014; Malmberg et al., 2015) that more successful outcome groups are better able to resolve problems, misunderstandings, and uncertainties that emerged during the activity because they regulated their shared thinking and problem solving more effectively. In the American university engineering context, however, the less successful outcome group focused more on high level cognitive activity than the more successful outcome group. This finding differed from the premise that the presence of MR in high-cognitive level learning processes leads to successful learning outcome (see Brown, 1978; Flavell, 1976) and from previous research in collaborative learning where MR's focus on high-level cognitive activity has been highlighted (e.g. Grau \& Whitebread, 2012; Iiskala et al., 2011; Järvelä et al., 2013; Khosa \& Volet, 2014; Malmberg et al., 2015; Ucan \& Webb, 2015). However, one of the limitations of the present study is that the difference in outcome metric between the selected groups in the engineering context was not as large at the other contexts. Future research should continue to explore the MR processes of extreme groups but also include groups performing at intermediate levels, in order to gain further insight into the relationship between MR processes and degree of success in outcome in different contexts.

In the case of the Australian university veterinary science students, the interplay of the forms and foci of their MR (RQ3) revealed that the form was predominantly SSMR, with its foci on high- (64.9\% in the more successful outcome group) or low-level (75.5\% in the less successful outcome group) cognitive activity. Conversely, this interaction of forms and foci was different for the Finnish high school science students. Irrespective of the form of MR (MOR or SSMR), MR processes were more prominent in the more successful outcome group focusing on high-level cognitive activity (MOR 29.1\%; SSMR 37.9\%) more than in the less successful group (MOR 13.1\%; SSMR 9.9\%). Finally, a different interplay between the forms and foci of MR was evident in the American university engineering context, where the less successful outcome group showed relatively more SSMR of highlevel (63.4\% vs. $25.0 \%$ at low level) cognitive activity, whereas the more successful outcome group's SSMR was more equally divided between the high (38.7\%) and low (46.7\%) cognitive levels, however, focusing more on low-level cognitive activity.

Concerning both RQ2 and RQ3, one explanation for these findings among engineering students who are nearing graduation is that the more successful outcome group's professional competence was well developed and to some extent already automated (cf. Vygotsky's notion on fossilisation, see Holland \& Valsiner, 1988); thus, they did not need as much high cognitive level discourse to effectively proceed. This explanation 
is consistent with previous research on expertise in a medical context (Boshuizen \& Schmidt, 2008), which revealed that experts' reasoning is often implicit, automatic, and unconscious, and only verbalised in cases of mismatches or conflicts. In other words, MR may run in the background of the cognitive processes being executed and activated only when needed, for example, when difficulties or unexpected results are encountered (Järvelä et al., 2013; Veenman, Van Hout-Wolters, \& Afflerbach, 2006). This conjecture is supported by the relatively high performance scores of all the groups in the American university engineering context. It is also possible that the more successful outcome engineering group was better able to use routinised knowledge relative to the less successful outcome group due to nature of the task. The less successful outcome group may have made more mistakes and had more uncertainties in their process, which in turn required more MR (see Goos, 2002) and made the task more complex (see DiDonato, 2013) to this group. The qualitative illustrations from the American engineering context show that students in the more successful small group seemed to reach a collective understanding early in the process but the less successful group had to regulate the process more to make sense of the complex task. Thus, high task complexity could activate MR (see DiDonato, 2013; Iiskala et al., 2011) in the less successful group in the American engineering context.

As one part of the possible explanation is that as a "capstone project," the engineering task asked students to draw upon and integrate concepts and skills from earlier courses in the curriculum, and the more successful outcome group likely had already internalised this content. In this sense, the more successful outcome group may had been more familiar with the content of the task (see Sockalingam \& Schmidt, 2013). This conjecture is consistent with the observation that the more successful outcome group had a lower proportion of turns at high cognitive level, but were able to effectively regulate those high-level interactions when needed. The findings of the American university engineering groups suggest that not all MR emerges in groups' verbal interaction. Instead, a sign of MR can be that it does not manifest in verbal interaction in situations when MR is not needed. From a practical perspective, teachers need to be careful about how they respond to a group's collaborative learning processes. For example, if the group is progressing fluently towards a successful outcome, MR may not be needed. In that sense, MR in productive collaborative learning can also consist of the absence of observable MR from verbal interactions. This finding suggests the need to study MR from non-verbal communication in collaborative learning as well.

Finally, this finding could be attributed to sampling issues. Although the analysed segments were carefully selected, those selected for the more successful outcome American university engineering group could have been at a point where the work was less complex and they may have focused SSMR in parts that were more complex but not studied here. From this perspective, one limitation of the present study is that the entire group activity was not analysed. Importantly, we cannot make generalisations from this exploratory case study, and thus, more groups should be analysed in future.

We employed a holistic, situative perspective of context, positing that a learner's behavior within the collaborative group is inseparable from the social and cultural context that learning takes place. Based on this perspective, we have prioritised authentic learning experiences that align with disciplinary practices over more constrained activity that allows for greater experimental rigour (see also Grau et al., 2018). Such validity is important, since authentic activities are crucial to support thinking and doing in disciplines (see Engle, 2012; Koretsky et al., 2019; Vauras, Volet, \& Nolen, 2019). For example, engineering schools typically draw on the disciplinary culture of engineering 
(see Carberry \& Baker, 2018). To date, however, there is limited empirical research on the relationship between metacognition and culture in engineering (Dori et al., 2018). In addition to being conditioned within a particular discipline, formal learning also occurs within schools, each with their own culture. Thus, the manifestation of MR by students working in a large, public university in the USA, for example, can differ from students undertaking a similar activity in other settings. While the present study provides some empirical data for this less explored American engineering context, more research on the effect of learning culture and its relation to MR's forms and foci are warranted.

\section{Conclusions}

The present study provided empirical support for the criticality of going beyond the study of MR as a single umbrella concept and unpacking its key characteristics such as its different forms and foci. Indeed, as revealed in this study, different forms and foci of MR occur and play distinct, meaningful roles during a group's collaborative learning process (see also Grau \& Whitebread, 2012; Molenaar et al., 2014; Rogat \& AdamsWiggins, 2014; Volet et al., 2013). In other words, it is not the amount of MR that is crucial but the interplay of MR's forms and foci. Thus, more research of the unique and interactive effects of forms and foci is needed, both with novice and advanced learners, in diverse learning and cultural contexts. Analyses of the fluctuation of MR, both in terms of forms and foci, and non-regulative cognitive activity (e.g. scientific argumentation) throughout the collaborative activity (applying e.g. sequential analysis) would further deepen our understanding of patterns underlying productive learning.

A key feature of the present study was to use the same conceptualisation of MR, its forms and foci, and to adopt the same analytical method, including the same coders, across three diverse contexts, which varied in academic level, disciplinary subject, and national culture. Caution is needed when coding MR in collaborative learning. One of the first steps in the process is to determine which observable behaviour is to be recognised and coded as MR and which is not. Inferences are not straightforward across very different tasks and contexts (see also Mathabathe \& Potgieter, 2017; Whitebread et al., 2009). However, we would argue that, as demonstrated in the present study, using the same coders and the same conceptual tools across all studied cases helped to mitigate these issues. Furthermore, the coded data could be meaningfully complemented by qualitative illustrations which provided further insight into the dynamics of MR in context.

As demonstrated here, not even collaborative science learning contexts that are explicitly designed to promote groups' productive engagement (see e.g., Malmberg, Järvelä, \& Kirschner, 2014; Vauras et al., 2019) necessarily prompt the generation of shared goals to go into deep-level engagement with the scientific activity and effective manifestation of MR in collaborative processes. Observable MR processes do not automatically play a productive role in the quality of a group's outcome in collaborative learning. Contextual and interaction factors must be carefully taken into consideration. Thus, to conclude, the present study suggests that we cannot axiomatically and directly transfer the findings of one context to another, for example, from individual learning to collaborative learning, but also from one collaborative learning context to another, or even from one group to another within the same learning activity. Contextual features 
may cause variations in the emergence of MR in terms of forms and foci in collaborative learning processes of different outcome groups.

\section{Appendix 1}

\section{Description of collaborative learning contexts}

\section{Senior high school general science in Finland}

A web-based learning environment, Virtual Baltic Sea Explorer, was designed to offer a realistic research context for learning key scientific concepts integrating biology and chemistry, fostering scientific reasoning skills, and becoming acquainted with authentic scientific practices and experimental scientific methods. The group activity involved designing and running an experiment on the effects of $\mathrm{pH}$ changes on phytoplankton and copepods in the context of the Baltic Sea's food chain. A rich set of virtual tools (such as a library, researcher interviews, laboratory tasks, and external internet links) and the collaborative nature of the activity created opportunities for deep-level learning.

\section{Second-year university veterinary science in Australia}

A collaborative clinical case-based assignment, representing students' first exposure to authentic clinical case material, was designed to offer an opportunity to apply foundational preclinical knowledge from multiple disciplinary subjects that they had studied thus far. This included extracting relevant anatomy- and physiology-based clinical concepts and investigating the underlying principles of treatment and management of the various disease processes related to the case. Two group activities were studied: generation of learning objectives related to the case; and construction of a concept map of that case using a set of cards, each describing one feature. The cards had to be arranged in a meaningful manner, leaving out concepts not relevant to the case, and drawing either unidirectional arrows to represent cause and effect relationships or bidirectional arrows to indicate relationships between concepts.

\section{Fourth-year university engineering in the United States}

The VCVD process project was designed to provide a bridge between university and industry by adopting the practices, values, and goals of an industrial work team in a professional context. In this open-ended design task, student groups developed a "recipe" of input parameters for a virtual industrial reactor while considering competing constraints. They used the reactor as they would in the industry-to optimise reactor performance based on experimentation. Since students were charged money for experiments, unstructured trial and error approaches were discouraged and they were required to integrate their fundamental engineering science knowledge in developing their "recipe." Before groups were allowed access to perform experiments, they needed to have a design memorandum (studied here) approved. 


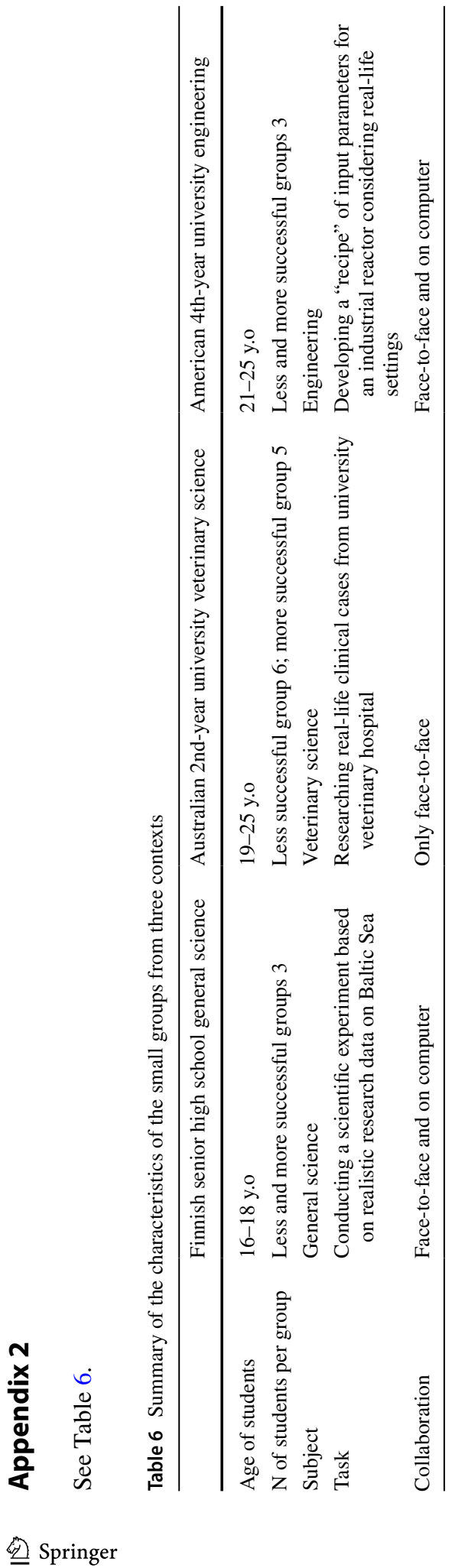


Author contributions All of the authors listed in the byline have contributed to the manuscript and agreed to the byline order of the manuscript in this form.

Funding Open access funding provided by University of Turku (UTU) including Turku University Central Hospital. This study was funded by the Council of Cultural and Social Science Research, Academy of Finland (Grant Nos. 268936 and 274117) to the fifth author; the Australian Research Council's Discovery Projects Funding Scheme (Project Number DP0986867) to the second author; and the US National Science Foundation (Grant No. EEC 1261930) to the fourth author.

Data availability Not applicable. The small scale and highly qualitative nature of this study prevents making the data available for others to use. The data consist of video and audio data that cannot be made available for others for ethical/anonymity reasons.

Code availability Not applicable.

\section{Declarations}

Conflict of interest The authors have no conflicts of interest to declare that are relevant to the content of this article.

Ethical approval Finnish context: in all aspects, this research followed carefully the guidelines of the Finnish National Board of Research Integrity (TENK) and Ethics Committee of the University of Turku as well as data security demands of the University. Approval from the Ethics Committee was not needed for this type of study at the time in Finland. Australian context: this research was formally approved by Murdoch University Human Research Ethics Committee. The authorisation was received on 29 June 2009 and the Ethics Permit Number was $2009 / 156$. The US context: this research was approved by the Oregon State University Institutional Review Board under study \#3660.

Open Access This article is licensed under a Creative Commons Attribution 4.0 International License, which permits use, sharing, adaptation, distribution and reproduction in any medium or format, as long as you give appropriate credit to the original author(s) and the source, provide a link to the Creative Commons licence, and indicate if changes were made. The images or other third party material in this article are included in the article's Creative Commons licence, unless indicated otherwise in a credit line to the material. If material is not included in the article's Creative Commons licence and your intended use is not permitted by statutory regulation or exceeds the permitted use, you will need to obtain permission directly from the copyright holder. To view a copy of this licence, visit http://creativecommons.org/licenses/by/4.0/.

\section{References}

Akyol, G., Sungur, S., \& Tekkaya, C. (2010). The contribution of cognitive and metacognitive strategy use to students' science achievement. Educational Research and Evaluation, 16(1), 1-21. https://doi.org/ $10.1080 / 13803611003672348$

Boshuizen, H. P. A., \& Schmidt, H. G. (2008). The development of clinical reasoning expertise: Implications for teaching. In J. Higgs, M. Jones, S. Loftus \& N. Christensen (Eds.), Clinical reasoning in the health professions (3rd comp. rev. ed., pp. 113-121). Butterworth-Heinemann/Elsevier.

Brown, A. L. (1978). Knowing when, where, and how to remember: A problem of metacognition. In R. Glaser (Ed.), Advances in instructional psychology (Vol. 1, pp. 77-165). Erlbaum.

Brown, A. L., Bransford, J. D., Ferrara, R. A., \& Campione, J. C. (1983). Learning, remembering, and understanding. In P. H. Mussen (Ed.), J. H. Flavell \& E. M. Markman (Vol. Eds.), Handbook of child psychology: Cognitive development (Vol. 3, 4th ed., pp. 77-166). Wiley.

Carberry, A. R., \& Baker, D. R. (2018). The impact of culture on engineering and engineering education. In Y. J. Dori, Z. Mevarech \& D. Baker (Eds.), Cognition, metacognition, and culture in STEM education. Learning, teaching, and assessment (pp. 217-239). Springer. https://doi.org/10.1007/ 978-3-319-66659-4.

De Backer, L., Van Keer, H., \& Valcke, M. (2015). Exploring evolutions in reciprocal peer tutoring groups' socially shared metacognitive regulation and identifying its metacognitive correlates. Learning and Instruction, 38, 63-78. https://doi.org/10.1016/j.learninstruc.2015.04.001 
DiDonato, N. C. (2013). Effective self- and co-regulation in collaborative learning groups: An analysis of how students regulate problem solving of authentic interdisciplinary tasks. Instructional Science, 41(1), 25-47. https://doi.org/10.1007/s11251-012-9206-9

Dillenbourg, P. (1999). Introduction: what do you mean by "collaborative learning"? In P. Dillenbourg (Ed.), Collaborative learning. Cognitive and computational approaches (pp. 1-19). Elsevier.

Dori, Y. J., Mevarech, Z. R., \& Baker, D. (2018). Introduction. In Y. J. Dori, Z. Mevarech \& D. Baker (Eds.), Cognition, metacognition, and culture in STEM education. Learning, teaching, and assessment (pp. 1-8). Springer. https://doi.org/10.1007/978-3-319-66659-4.

Efklides, A. (2008). Metacognition: Defining its facets and levels of functioning in relation to self-regulation and co-regulation. European Psychologist, 13(4), 277-287. https://doi.org/10.1027/1016-9040. 13.4.277

Engeström, Y. (2001). Expansive Learning at Work: Toward an activity theoretical reconceptualization. Journal of Education and Work, 14(1), 133-156. https://doi.org/10.1080/13639080020028747

Engle, R. A. (2012). The productive disciplinary engagement framework: Origins, key concepts and developments. In Y. Dai (Ed.), Design research on learning and thinking in educational settings: Enhancing intellectual growth and functioning (pp. 161-200). Routledge. https://doi.org/10.4324/9780203849 576.

Flavell, J. H. (1976). Metacognitive aspects of problem-solving. In L. B. Resnick (Ed.), The nature of intelligence (pp. 231-235). Lawrence Erlbaum.

Goos, M. (2002). Understanding metacognitive failure. Journal of Mathematical Behavior, 21(3), 283-302. https://doi.org/10.1016/S0732-3123(02)00130-X

Grau, V., Lorca, A., Araya, C., Urrutia, S., Ríos, D., Montagna, P., \& Ibaceta, M. (2018). Socially shared regulation of learning and quality of talk: Age differences in collaborative group work in classroom contexts. New Directions for Child and Adolescent Development, 162, 11-39. https://doi.org/10.1002/ cad.20261

Grau, V., \& Whitebread, D. (2012). Self and social regulation of learning during collaborative activities in the classroom: The interplay of individual and group cognition. Learning and Instruction, 22(6), 401-412. https://doi.org/10.1016/j.learninstruc.2012.03.003

Greeno, J. G. (2006). Learning in activity. In R. K. Sawyer (Ed.), The Cambridge handbook of the learning sciences (pp. 79-96). Cambridge University Press.

Hadwin, A., \& Oshige, M. (2011). Self-regulation, coregulation, and socially shared regulation: Exploring perspectives of social in self-regulated learning theory. Teachers College Records, 113(2), 240-264.

Hargreaves, E. (2007). The validity of collaborative assessment for learning. Assessment in Education, 14(2), 185-199. https://doi.org/10.1080/09695940701478594

Holland, D. C., \& Valsiner, J. (1988). Cognition, symbols, and Vygotsky's developmental psychology. Ethos, 16(3), 247-272. https://doi.org/10.1525/eth.1988.16.3.02a00020

Iiskala, T., Vauras, M., \& Lehtinen, E. (2004). Socially-shared metacognition in peer learning? Hellenic Journal of Psychology, 1(2), 147-178.

Iiskala, T., Vauras, M., Lehtinen, E., \& Salonen, P. (2011). Socially shared metacognition of dyads of pupils in collaborative mathematical problem-solving processes. Learning and Instruction, 21(3), 379-393. https://doi.org/10.1016/j.learninstruc.2010.05.002

Iiskala, T., Volet, S., Lehtinen, E., \& Vauras, M. (2015). Socially shared metacognitive regulation in asynchronous CSCL in science: Functions, evolution and participation. Frontline Learning Research, 3(1), 78-111. https://doi.org/10.14786/flr.v3i1.159

Isohätälä, J., Näykki, P., \& Järvelä, S. (2020). Convergences of joint, positive interactions and regulation in collaborative learning. Small Group Research, 51(2), 229-264. https://doi.org/10.1177/1046496419 867760

Janssen, J., Erkens, G., Kanselaar, G., \& Jaspers, J. (2007). Visualization of participation: Does it contribute to successful computer-supported collaborative learning? Computers and Education, 49(4), 10371065. https://doi.org/10.1016/j.compedu.2006.01.004

Järvelä, S., Järvenoja, H., Malmberg, J., \& Hadwin, A. (2013). Exploring socially-shared regulation in the context of collaboration. The Journal of Cognitive Education and Psychology, 12(3), 267-286. https:// doi.org/10.1891/1945-8959.12.3.267

Järvelä, S., Malmberg, J., \& Koivuniemi, M. (2016). Recognizing socially shared regulation by using temporal sequences of online chat and logs in CSCL. Learning and Instruction, 42, 1-11. https://doi.org/ 10.1016/j.learninstruc.2015.10.006

Järvenoja, H., Järvelä, S., \& Malmberg, J. (2015). Understanding regulated learning in situative and contextual frameworks. Educational Psychologist, 50(3), 204-219. https://doi.org/10.1080/00461520.2015. 1075400 
Johri, A., Olds, B. M., \& O'Connor, K. (2014). Situative frameworks for engineering learning research. In A. Johri \& B. M. Olds (Eds.), Cambridge handbook of engineering education research (pp. 47-66). Cambridge University Press.

Kempler, T. M., \& Linnenbrink, E. A. (2006). Helping behaviors in collaborative groups in math: A descriptive analysis. In S. A. Karabenick \& R. S. Newman (Eds.), Help seeking in academic settings: Goals, groups, and contexts (pp. 89-116). Routledge.

Khosa, D. K., \& Volet, S. (2014). Productive group engagement in cognitive activity and metacognitive regulation during collaborative learning: Can it explain differences in students' conceptual understanding? Metacognition and Learning, 9(3), 287-307. https://doi.org/10.1007/s11409-014-9117-z

Koretsky, M. D., Vauras, M., Jones, C., Iiskala, T., \& Volet, S. (2019). Productive disciplinary engagement in high and low-outcome student groups: Observations from three collaborative science learning contexts. Research in Science Education. https://doi.org/10.1007/s11165-019-9838-8

Lajoie, S. P., \& Lu, J. (2012). Supporting collaboration with technology: Does shared cognition lead to co-regulation in medicine? Metacognition and Learning, 7(1), 45-62. https://doi.org/10.1007/ s11409-011-9077-5

Landis, J. R., \& Koch, G. G. (1977). The measurement of observer agreement for categorical data. Biometrics, 33(1), 159-174. https://doi.org/10.2307/2529310

Malmberg, J., Järvelä, S., \& Järvenoja, H. (2017). Capturing temporal and sequential patterns of self-, co-, and socially shared regulation in the context of collaborative learning. Contemporary Educational Psychology, 49, 160-174. https://doi.org/10.1016/j.cedpsych.2017.01.009

Malmberg, J., Järvelä, S., Järvenoja, H., \& Panadero, E. (2015). Promoting socially shared regulation of learning in CSCL: Progress of socially shared regulation among high- and low-performing groups. Computers in Human Behavior, 52, 562-572. https://doi.org/10.1016/j.chb.2015.03.082

Malmberg, J., Järvelä, S., \& Kirschner, P. A. (2014). Elementary school students' strategic learning: Does task-type matter? Metacognition and Learning, 9(2), 113-136. https://doi.org/10.1007/ s11409-013-9108-5

Mathabathe, K. C., \& Potgieter, M. (2017). Manifestations of metacognitive activity during the collaborative planning of chemistry practical investigations. International Journal of Science Education, 39(11), 1465-1484. https://doi.org/10.1080/09500693.2017.1336808

Molenaar, I., Roda, C., van Boxtel, C., \& Sleegers, P. (2012). Dynamic scaffolding of socially regulated learning in a computer-based learning environment. Computers and Education, 59(2), 515-523. https://doi.org/10.1016/j.compedu.2011.12.006

Molenaar, I., Sleegers, P., \& van Boxtel, C. (2014). Metacognitive scaffolding during collaborative learning: A promising combination. Metacognition and Learning, 9(3), 309-332. https://doi.org/10.1007/ s11409-014-9118-y

Nguyen, H., Lim, K. Y., Wu, L. L., Fischer, C., \& Warschauer, M. (2021). "We're looking good”: Social exchange and regulation temporality in collaborative design. Learning and Instruction. https://doi.org/ 10.1016/j.learninstruc.2021.101443

Panadero, E., \& Järvelä, S. (2015). Socially shared regulation of learning: A review. European Psychologist, 20(3), 190-203. https://doi.org/10.1027/1016-9040/a000226

Peters, E. E., \& Kitsantas, A. (2010). Self-regulation of student epistemic thinking in science: The role of metacognitive prompts. Educational Psychology, 30(1), 27-52. https://doi.org/10.1080/0144341090 3353294

Pintrich, P. R., \& De Groot, E. V. (1990). Motivational and self-regulated learning components of classroom academic performance. Journal of Educational Psychology, 82(1), 33-40. https://doi.org/10.1037/ 0022-0663.82.1.33

Rogat, T. K., \& Adams-Wiggins, K. R. (2014). Other-regulation in collaborative groups: Implications for regulation quality. Instructional Science, 42(6), 879-904. https://doi.org/10.1007/s11251-014-9322-9

Rogat, T. K., \& Linnenbrink-Garcia, L. (2011). Socially shared regulation in collaborative groups: An analysis of the interplay between quality of social regulation and group processes. Cognition and Instruction, 29(4), 375-415. https://doi.org/10.1080/07370008.2011.607930

Roschelle, J., \& Teasley, S. D. (1995). The construction of shared knowledge in collaborative problem solving. In C. O’Malley (Ed.), Computer supported collaborative learning (pp. 69-97). Springer. https:// doi.org/10.1007/978-3-642-85098-1_5.

Schoor, C., \& Bannert, M. (2012). Exploring regulatory processes during a computer-supported collaborative learning task using process mining. Computers in Human Behavior, 28(4), 1321-1331. https://doi. org/10.1016/j.chb.2012.02.016

Schoor, C., Narciss, S., \& Körndle, H. (2015). Regulation during cooperative and collaborative learning: A theory-based review of terms and concepts. Educational Psychologist, 50(2), 97-119. https://doi.org/ $10.1080 / 00461520.2015 .1038540$ 
Sockalingam, N., \& Schmidt, H. G. (2013). Does the extent of problem familiarity influence students' learning in problem-based learning? Instructional Science, 41(5), 921-932. https://doi.org/10.1007/ s11251-012-9260-3

Ucan, S. (2017). Changes in primary school students' use of self and social forms of regulation of learning across collaborative inquiry activities. International Journal of Educational Research, 85, 51-67. https://doi.org/10.1016/j.ijer.2017.07.005

Ucan, S., \& Webb, M. (2015). Social regulation of learning during collaborative inquiry learning in science: How does it emerge and what are its functions? International Journal of Science Education, 37(15), 2503-2532. https://doi.org/10.1080/09500693.2015.1083634

Vauras, M., Volet, S., \& Iiskala, T. (2021). Metacognitive regulation in collaborative science education. In D. Moraitou \& P. Metallidou (Eds.), Trends and prospects in metacognition research across the life span-A tribute to Anastasia Efklides (pp. 83-102). Springer.

Vauras, M., Volet, S., \& Nolen, S. B. (2019). Supporting motivation in collaborative learning: Challenges in the face of an uncertain future. In S. Karabenick \& T. C. Urdan (Eds.), Motivation in Education at a time of global change (pp. 187-203). Emerald Publishing.

Veenman, M., \& Elshout, J. J. (1999). Changes in the relation between cognitive and metacognitive skills during the acquisition of expertise. European Journal of Psychology of Education, 14(4), 509-523. https://doi.org/10.1007/BF03172976

Veenman, M., Van Hout-Wolters, B. H. A. M., \& Afflerbach, P. (2006). Metacognition and learning: Conceptual and methodological considerations. Metacognition and Learning, 1(1), 3-14. https://doi.org/ 10.1007/s11409-006-6893-0

Volet, S., \& Summers, M. (2013). Interpersonal regulation in collaborative learning activities: Reflections on emerging research methodologies. In S. Volet \& M. Vauras (Eds.), Interpersonal regulation of learning and motivation: Methodological advances (pp. 204-220). Routledge. https://doi.org/10.4324/ 9780203117736.

Volet, S., Summers, M., \& Thurman, J. (2009a). High-level co-regulation in collaborative learning: How does it emerge and how is it sustained? Learning and Instruction, 19(2), 128-143. https://doi.org/10. 1016/j.learninstruc.2008.03.001

Volet, S., Vauras, M., Khosa, D., \& Iiskala, T. (2013). Metacognitive regulation in collaborative learning: Conceptual developments and methodological contextualizations. In S. Volet \& M. Vauras (Eds.), Interpersonal regulation of learning and motivation: Methodological advances (pp. 67-101). Routledge. https://doi.org/10.4324/9780203117736.

Volet, S., Vauras, M., Salo, A.-E., \& Khosa, D. (2017). Individual contributions in student-led collaborative learning: Insights from two analytical approaches to explain the quality of group outcome. Learning and Individual Differences, 53, 79-92. https://doi.org/10.1016/j.lindif.2016.11.006

Volet, S., Vauras, M., \& Salonen, P. (2009b). Self- and social regulation in learning contexts: An integrative perspective. Educational Psychologist, 44(4), 215-226. https://doi.org/10.1080/00461520903213584

Vukman, K. B. (2005). Developmental differences in metacognition and their connections with cognitive development in adulthood. Journal of Adult Development, 12(4), 211-221. https://doi.org/10.1007/ s10804-005-7089-6

Wang, M. C., Haertel, G. D., \& Walberg, H. J. (1990). What influences learning? A content analysis of review literature. Journal of Educational Research, 84(1), 30-43. https://doi.org/10.1080/00220671. 1990.10885988

Wenger, E., McDermott, R., \& Snyder, W. (2002). Cultivating communities of practice: A guide to managing knowledge. Harvard Business School Press.

Whitebread, D., Coltman, P., Pino Pasternak, D., Sangster, C., Grau, V., Bingham, S., Almeqdad, Q., \& Demetriou, D. (2009). The development of two observational tools for assessing metacognition and self-regulated learning in young children. Metacognition and Learning, 4(1), 63-85. https://doi.org/10. 1007/s11409-008-9033-1

Zheng, J., Xing, W., \& Zhu, G. (2019). Examining sequential patterns of self- and socially shared regulation of STEM learning in a CSCL environment. Computers and Education, 36, 34-48. https://doi.org/10. 1016/j.compedu.2019.03.005

Publisher's Note Springer Nature remains neutral with regard to jurisdictional claims in published maps and institutional affiliations. 